\title{
Enriching creative communities through Young Adult (YA) literature: a content analysis of zines from Philippine High School for the Arts
}

Reya Mari Soriaga Veloso

University of the Philippines Los Baños, Philippines, rsveloso@up.edu.ph

Follow this and additional works at: https://scholarhub.ui.ac.id/ajce

Part of the Children's and Young Adult Literature Commons, Liberal Studies Commons, and the Reading and Language Commons

\section{Recommended Citation}

Veloso, Reya Mari Soriaga (2020). Enriching creative communities through Young Adult (YA) literature: a content analysis of zines from Philippine High School for the Arts. ASEAN Journal of Community Engagement, 4(1).

Available at: https://doi.org/10.7454/ajce.v4i1.1071

Creative Commons License

\section{(c) (7) (2)}

This work is licensed under a Creative Commons Attribution-Share Alike 4.0 License.

This Research Article is brought to you for free and open access by the Universitas Indonesia at ASEAN Journal of Community Engagement. It has been accepted for inclusion in ASEAN Journal of Community Engagement. 
Enriching creative communities through Young Adult (YA)

literature: a content analysis of zines from Philippine High School

for the Arts

\author{
Reya Mari Soriaga Veloso ${ }^{*}$ \\ aUniversity of the Philippines Los Baños, Philippines
}

Received: January $9^{\text {th }}, 2020||$ Revised: May $4^{\text {th }} \& 12^{\text {th }}, 2020||$ Accepted: July $29^{\text {th }}, 2020$

\begin{abstract}
Prompted by the recent boom of zine-making and the active participation of youth in the local art scene, this paper is focused on determining the role of zines in the lives, culture of creation, and community engagement of young adults (YAs) and creating a typology based on the coming-ofage themes presented in fiction and nonfiction zines created by students at Philippine High School for the Arts (PHSA). To do so, the researcher collected zines from various events and expos, chose zines written by YAs (PHSA students in particular), conducted focus-group and individual interviews among the authors, and performed content analysis on all the materials collected. The results indicate that zines are used for self-expression, community building, and self-publishing. Moreover, themes such as permanence versus transience, relationship-building, nostalgia, language as a shaper of identity, and acts of subversion are common among coming-ofage narratives. Finally, this study was able to conclude that YA zines are a form of counterstorytelling, provide an alternative creative community to the youth, and act as a means for sociological theorizing, all of which are necessary functions for enriching creative communities among the youth.
\end{abstract}

Keywords: Young Adult literature; zines; creative communities; counter-storytelling; content analysis.

\title{
1. Introduction
}

\subsection{The Zine}

Zines (pronounced "zeens") are informal, handmade magazines self-published by their creators (Duncombe, 2008). Given these characteristics, the pfroduction of zines is ephemeral, as each copy or issue only runs for a limited time depending on the capability and the resources of the creator to reproduce them. Zines often include some combination of visual art, photographs, poems, short fictions, and short essays. Zinemaking has forged creative communities among writers, creators, and artists where they can engage with people who share the same structures of feelings, nurturing a space for self-expression and continuous creation among them.

*Correspondence Author: rsveloso@up.edu.ph 
Zines are a very nuanced form of publication and literature. Over the years, they have transitioned from handmade cut-outs to black-and-white photocopies to colored prints, but they remain part of an alternative and minor form of literature. While the physicality of the zines has transformed alongside the technology available to publish and print them, they still espouse radical sensibilities and have become a means of unfettered expression, especially to young writers who have chosen self-publication as the first step to publicizing and distributing their work. Most zine creators and consumers come from the youth sector, as the zine scene has become an answer for the urgent need of young people to have a safe space for self-expression. Chu (1997, p. 73) affirms this by saying that zines "articulate young people's strong need for a place of their own, despite the vanishing of such public spaces from the material environment". Furthermore, this inspires the call for "zines and other forms of youth-initiated media" to be taken seriously, as they are now deemed to be the "new authentic voice of youths" (Chu, 1997). Zines give young people agency: the power to create and produce their own work, an entrance to public readership, and the freedom to write about subjects and themes that are relevant to their experiences while remaining exempt from the stringent requirements of mainstream publishers.

Since its inception in Quezon City in 2010, Better Living through Xeroxography, known among creative and creative communities as $B L T X$, has been a reliable avenue for small press and independent publishing. BLTX is usually a one-day annual event where writers and artists come together to showcase and sell their work, and as of writing, BLTX has expanded beyond the metro and has established chapters in Naga, Baguio, Davao and Cagayan de Oro (Cabral \& Ledesma, 2016). Struggling writers or visual artists who feel inhibited or dissatisfied with the requirements of commercial sponsors and mainstream publishing often find that BLTX and similar expos to be a viable alternative for producing and circulating their work.

Siriban (2010, p. 4) defines zines as "works imbued with values, thoughts, feelings of smaller groups, and may coincide with or negotiate existing understandings of concepts, relations, and conditions of social life". Her thesis, entitled "Zines in Philippine Punk Culture: A Textual Analysis of Creative Nonfiction in Southern Tagalog Zines," focused on substantiating creative nonfiction in zines as residual-emergent products of punk culture rather than just the ephemera of emergent or counterculture, revealing structures of feelings or "patterns of ideas loosely formed by the conscious decisions 
Reya Mari Soriaga Veloso | ASEAN Journal of Community Engagement | Volume 4, Number 1, 2020

made by zine writers in the constructions of their texts" through strategies or devices such as character, persona, language, mood, or tone. Examples of structures of feelings uncovered in analyzing creative nonfiction in zines include: resistance against societal expectations on adulthood; rejection of the current labor-capital system and workplace conditions; a fascination with commercial industries promoting Western humor and lifestyle; diaspora; questioning the patriarchy; a critique and reevaluation of the concept of family as a social institution; and even a protest against the seemingly Western roots of punk culture in the Philippines. Siriban (2010) claims that these structures of feelings sustain the power of subjectivities and create "minor disturbances" that alter or modify the meanings of existing concepts, eventually affecting readers of the zine culture no matter how small it may be.

\subsection{The Zinesters}

Preliminary findings of this investigation indicate that young adults (YAs) make up the majority of participants in zine-making. This study defines adolescents and YAs as those belonging to the age range of 12-24 years old. According to Butow et al. (2010), adolescents and YAs, or AYAs, are aged 12 to 24 years. Zine expos are often spearheaded by student-artists and student-writers who also produce zines. YAs within the circle of zine-makers may regard it as pop culture but viewed from mainstream and traditional perspective of print and publications, zines are considered minor literature. Most of the zines collected from WiSiK, a University zine convention, held in September 2017 were written and produced by AYAs from both high school and tertiary levels. This is important to note, as the genre of YA literature has been very difficult to define in terms of readership. However, a new study suggests that $55 \%$ of books produced for 12-17-year-olds are actually read by those who are 18 and older (Howlett, 2015). The scientific age range of AYAs supports the finding that YA literature has expanded in age range. Since students from high school up to tertiary level fall into the category of AYAs, it should be assumed that they are also active consumers and producers of YA literature, which can also be explored in the zines that they create.

Coming-of-age is the transition from youth to adulthood. In literature, it depicts protagonist encountering specific passage rites into adulthood. Western literature often depicts coming-of-age through themes of sex, drugs, and alcohol. Often, YA fiction and nonfiction are written by much older authors. While YA literature by Filipino authors is 
still not widely consumed as those by foreign ones, their depiction of coming-of-age is more organic and more reflective of the Filipino experience. Alongside YA literature that is produced and consumed through commercial channels, high school students from Philippine High School for the Arts (PHSA) independently produce their own coming-ofage narratives through zine-making.

\subsection{The Zine scene (and creative communities)}

The community of zine-makers or zinesters in the Philippines may be new, but their roots have always been present. These groups are made up of young people who are already engaged in creating their own works of art: photography, cartooning, drawing, painting, writing, etc. Some of them might come from university organizations that are immersed in conducting and facilitating group workshops for the specific art genres they cater to, while others are unaffiliated aficionados of the craft. These young people are hungry for connections and are eager for their work to reach a wider audience. Duncombe (2008) discusses that while zinesters are often susceptible to their loneliness as making zines are somehow an individualistic endeavor, the primary goal of zinesters is still to communicate; thus, the yearning for an audience to feel connected is always present. In other words, the eagerness not just to be a part of, but to actively build a community, is always inherent in a zinester.

With BLTX entering as a convention for zinesters and other creators to showcase their work, young people and other aficionados now have a place to go to if they want to meet fellow artists or just to read and purchase zines. BLTX sparked the zine scene in the Philippines. A few years after its inception, some literary and art groups in UPLB have been successful in launching similar events such as ElbiKon, WiSiK, Zine Orgy, and even off-campus events such as Munzinelupa (a creative take on the event name, as it will be held in Muntinlupa City). The scene is ripe with young people who are expressive and distinct in their choice of clothing as well as their precise preferences in film, literature, and music. Often, these people feel a sense of community in coming to these zine scenes as they are able to find like minds that they can talk to about topics they feel alienated from talking about such as politics, religion, and art.

These young people often feel that their opinions about these topics go against the mainstream, and this can result in feeling of displacement from their homes, schools, or even religious institutions. Duncombe (2008, p. 57-58) writes, "if community is 
Reya Mari Soriaga Veloso | ASEAN Journal of Community Engagement | Volume 4, Number 1, 2020

traditionally thought of as a homogeneous group of individuals bound together by their commonality, a zine network proposes something different: a community of people linked via bonds of difference, each sharing their originality". There is a joke among the art community that if you want to find out where the latest scene is, all you have to do is follow the people who seem to dress differently but are all carrying almost identical tote bags. The scene goes beyond these dated events and gatherings. Even after the zine event is over, they can take home the fellowship that they are able to build among their peers. "The Scene may not be a place, but it is a community" (Duncombe, 2008).

In the researcher's immersion in events such as ElbiKon, WiSiK, Zine Orgy, and Munzinelupa, most of the creators, producers, and consumers are AYAs. Moreover, preliminary data gathered from zines in the 2017 edition of WiSiK reveals that most of the zines in that event were written by college students in UPLB and high school students from PHSA. These YAs write poetry, fiction, and creative nonfiction pieces that mirror their varying perspectives of social reality and their coming-of-age narratives. The proliferation of YAs using zines as an avenue to produce their own work is a definitive statement that zine-making is, indeed, a "youth-initiated media" that needs to be further explored. Zobl (2009, p. 8) explains that zines "function as a space of active participation and for critical reflection-on one's self, one's community, society, and feminist activism and politics".

In zine scenes, whether the zine is personal, literary, or takes some other form such as comics, they always carry a message of advocacy. Therefore, zines are a preferred medium of those who are "ostracized, marginalized, or oppressed" (Cabral, 2017). They address topics such as bullying, academic struggles, developing awareness of mental illnesses, and even the displacement of Lumads, an indigenous group in the southern Philippines who are constantly harassed by military forces on their own territory at the behest of mining companies who want to take over their inherited lands. Much like editorial cartoons, many zine-makers satirize, parodize, and memeify current events, especially those that hamper the rights of the masses. Through zine-making, they acquire the stature and agency to criticize and react against such dominant figures that perpetuate epistemic violence; thus, zine-making becomes a community of selfempowered youth.

Teachers and the classroom also play a crucial role in ushering young zinesters to a community. Comstock (2001, p. 387) discusses, "in many writing classrooms, we have 
already begun to recognize how traditional notions of literacy, authorship, and the text marginalize viable alternative forms of writing and communication". Students who are seeking validation for the art and literature they consume and even for their radical opinions about politics and religion often find the classroom to be either a refuge or a snare. If teachers want to mold students into thoughtful citizens who are well-rounded and well-informed about the society around them, they must recognize the need to foster creative communities even beyond the classroom. In some arts and creative writing classes at UPLB, teachers allow their students to create a zine as a culmination of their classes.

The zine would hold a compilation of their students' best works or even just whatever art or creation the student would like to other people to see or read. This move to include the alternative form of zines within the mainstream regulations of a classroom encourages young people, even those who are not immersed in art and literature, to create and therefore establish fellowship and connection among fellow creators as they attempt to express themselves through their own zines. De Gravelles et al. (2012) documented how four eighth-grade classes were able to discuss and integrate YA themes of community through the use of "novelzines": "Beginning in a setting characterized by strong professional and student community, we considered how discussions of particular YA novels and the community-oriented writing practice of zines could combine to further students' understandings of community through what we came to call the "novelzine unit."

In turn, the students were more responsive and registered more of their expressions about themselves and their views of the community because of the zine aspect of their project. The students felt freer to express themselves personally, whether through essays or through rants and anecdotes. Workshops were also conducted to further integrate and assess the novelzine activity. Further, their study concludes that "these complex layers of connections to community allowed the team of teachers to extend their established professional community, engaging students in community building and discussions of a range of community issues through the novelzine project" (De Gravelles et al., 2012).

More than zine scenes or zine workshops, the materiality of zines is already a poignant site of community. Piepmeier (2008) pays attention to the physicality and the haptics of a zine as she concludes that every zine, because of its handmade and do-it- 
Reya Mari Soriaga Veloso | ASEAN Journal of Community Engagement | Volume 4, Number 1, 2020

yourself characters, provides an intimate link from the creator to its reader by just browsing through its pages. Whether it contains artful images, unstructured ramblings, or random photographs, the zine itself is a statement, a proclamation of a desire for a community. The zine is created to be read and designed to connect people by first connecting the creator to their readers.

Piepmeier (2008) likens zine communities to Iris Marion Young's "the ideal of city life" and Benedict Anderson's "imagined communities." Zines, no matter how different and individualized each piece might seem, are created for community engagement, especially among youth. Young people looking to foster meaningful connections as well as hone their creative sensibilities turn to zine-making, zine scenes, and zine workshops to actualize these goals. There is no specific geographical location for a zine community as it exists in liminal spaces that are occupied by the creator, the zine, its viewers, and the fellowship and the engagement that they foster. Zine scenes and zine events might be ephemeral, but the community engagement that is fostered and the creative communities assembled through these engagements will continue to exist for as long as people are creating zines and these zines have an audience.

\subsection{The future of Zines (and Young Adult literature)}

Studies on Philippine zines and their literary value are surprisingly scarce despite their proliferation in the last decade. Moreover, Filipino YA literature still lacks attention and reception from its target audience and readers, which are the Filipino youth themselves (Bongato \& Ting, 2014). Zine culture goes beyond self-publishing and making a mark in the alternative literary scene. The physical format of the zine provides readers with tactile pleasure (Estrella, 2016); moreover, "zines have a long history of accompanying subcultures and political movements around the world" (Cabral, 2017). No matter the social, political, or cultural context, zines contain political undertones.

Given that they are produced by writers and artists who are thwarted by stringent mainstream publishing requirements, the content of zines often belongs to the marginalized voices of the current dominant culture. Clearly, the contents in these selfpublished zines converge into a unified context of marginal or minor literature in the Philippines, which strengthens the argument that zine-making is a worthy site of scholarship, as the zines and their contents inform the developing landscape of 
literature in the Philippines as well as the dynamics of community engagement among the youth.

Guzzetti and Gamboa (2004) studied three high school-aged female zinesters. They conducted interviews and observations, which were triangulated by artifact collection: the zines that the girls created. They also conducted interviews with people close to the girls, such as their friends and family. They found out that three factors motivate these girls' zine-making: influences, support, and rewards. Influences such as internal anger against social injustice and resistance against mainstream culture are among the factors that enabled the girls' zine-making. Their zine-making was also supported by their socioeconomic status, their family, and their peers. Promotion, gaining publicity and more readerships were also a form of support that these zinesters received. Furthermore, their zine-making was rewarded by admiration, remuneration, and recognition from their peers. Understanding the motivations behind zine-making allows us to see how YAs make meaning through their chosen literary practices. Studies such as these allow us to deepen and widen the schema of what YA literature means for YAs.

While Alsup (2010) argues that YA literature has found acceptance and respect since its birth in the 1960s, she also agrees that scholarly examination of the genre is yet to be exhausted. YA literature is a genre that continuously improves and develops as it is informed by the lives of teens and adolescents around the globe. The process and transition from adolescence to adulthood varies across cultures and YA literature widens the birth of representation, especially for the lives of the youth who are silenced and marginalized. Filipino writers like Merlinda Bobis, Gabriela Lee, Eliza Victoria, Mina V. Esguerra, Edgar Calabia Samar, and many others have been contributing to the growing field of Filipino YA literature.

This goes to show that there are more writers now from varied ethnicities and cultures writing about coming-of-age narratives, reflective of how youths from other cultures grow up and face issues and struggles that inform how they are shaped from youth to adulthood. According to Wolk (2009), "Using YA literature is one of the most meaningful and enjoyable way for students to inquire into social responsibility because we can situate this content in the wonderful stories of good books. And within these stories are moral and ethical quandaries, just as they are in endless civic issues." How adolescents and YAs view society, family, marriage, gender, race, identity, and nation as concepts and as forces they find themselves struggling with are reflected in YA 
Reya Mari Soriaga Veloso | ASEAN Journal of Community Engagement | Volume 4, Number 1, 2020

literature. The failure to study the literature that most serves the youth is also a failure to usher and guide them toward a meaningful coming-of-age experience.

\subsection{The smaller histories and counter-storytelling in Zines}

The aim of introducing or including YA literature in the classroom is not just to entertain or to engage readers, but more importantly, to instill healthy and lifelong reading habits that will sustain and hone their critical-thinking skills and tap their cognitive and emotive responses to the world around them especially when they step out of the classroom. YA literature is part of multicultural counter-storytelling: literature that contains stories and themes of the marginalized sector, including narratives of ethnic and racial identities, abuse, and the spectrum of sexual identities and orientations (Hughes-Hassell, 2013). Multicultural YA literature challenges the single story: "the single story reinforces a deficit-oriented stance toward teens of color and indigenous peoples-a stance that represents their race, ethnicity, culture, and/or language as limitations" (Hughes-Hassell, 2013).

Not only does YA literature induce the interest of young adult readers, but it also gives them to understand that they have role in a larger narrative within their society or community, that their stories, no matter how minute they seem, are part of a larger social history. Whether they are struggling with poverty, abuse, dysfunctional families, mental health problems, or gender identity, reading about YA literature narratives that include reflections of their lives will shape the way they view the world around them.

Zines created by young people should also be regarded as YA literature. Their stories are no less worthy of scholarship than critically acclaimed (and seemingly much older) authors writing about coming-of-age stories. Erasga (2010) regards fiction as a reflection of reality and autobiography as a representation of smaller histories; he warns that one should not read fiction as removed from fact nor an autobiography as irrelevant to the collective history. This is crucial in reading and interpreting the stories written by YAs in their zines: what they write, whether in fiction or in creative nonfiction, will always reflect how they come-of-age given the cultural and socioeconomic milieu they belong to.

Although many Filipino writers now are delving into the genre of YA literature, there is a crucial ownership and authenticity of stories to those that are written by actual young adults. According to Erasga (2010, p. 21) "When Story Becomes Theory: 
Storytelling as Sociological Theorizing", "sociological imagination is an open invitation to theorize via the stories we tell ourselves and others". He posits that literary narratives are reflective of social reality and are therefore "legitimate materials for sociological theorizing" (Erasga, 2010). This validates that fiction and nonfiction produced by YAs through zines are legitimate part of our collective and even national history through their existence as smaller histories. The themes present in the what YAs write such as bullying, searching for a home, fitting in, establishing meaningful friendships, family life, abuse, domestic issues, and many others, whether fiction or nonfiction reflect the genuine experiences of our youth.

Furthermore, Erasga (2010) explains that every story counts, every narrative matters, as they are reflective of our social reality and are therefore vital in the interpretation of our current milieu. Literature reflects society and society shapes literature. For Erasga (2010, p. 23), reality is collected through stories and that storytelling is an act of "narrative mimesis" — an act that not only requires an audience, but also anticipates their participation, "a dynamic engagement between the author and the reader mediated by the text". Stories by our youth writes are crucial as they can document the collective sentiments of their peers, which in turn, reflect the narratives of a marginalized sector in society. Young people write or create not just for the sake of art or self-expression, but also because they are seeking an audience to connect to, an audience that will not just listen but also help address the issues that these young people are bringing forth through their fictions and nonfictions.

Moreover, Mojares (2015, p. 230) emphasizes that "to conceive of a national literature apart from the world is not possible". More than introducing YA literature to the classroom, this research envisions to shape a stronger definition of Filipino YA literature as part of Filipino literature. A teenager from Ilocos will not have the same experiences growing up as a teenager from Cebu, who will not have the same experiences as one from Marawi. While their stories remain Filipino in identity, their languages, cultures, and environment will remain distinct from each other. One of the goals of shaping Filipino YA literature is for these stories to come together and be read across regions so that the youth will have a deeper understanding of their own diversity. With this, we can strengthen and enrich creative communities that function as sites for fellowship and creation among YAs: forging spaces and alternative modes of 
Reya Mari Soriaga Veloso | ASEAN Journal of Community Engagement | Volume 4, Number 1, 2020

self-expression and artistic development that foster and hone stories and even the collection of small histories specific to the struggle and milieu of the youth.

This study is motivated by the surge and trend of zine-making in the Philippines since 2010 which results in the inevitable formation of creative communities among young people and their peers within and outside university. Additionally, this research is also interested in the use of young adult literature as a form of counter-storytelling and a means to collect smaller histories to engage the youth in narratives that are reflective of theirs. More importantly, this paper asserts that zine-making and young adult literature contain and reflect the ideals and realities of the Filipino youth and that these practices and forms of narratives translate into a radical discipline that not only engages the youth to form communities among themselves, but also mark their stories as part of the larger national history and should not be ignored.

\subsection{Research aims}

This paper has the following aims:

1. Determine the role of zines within the creative community of young adult zine writers in PHSA;

2. Analyze coming-of-age themes in selected fiction and creative nonfiction pieces from the zines; and

3. Create a thematic typology of coming-of-age themes in fiction and creative nonfiction in zines produced by PHSA students.

\section{Methods}

\subsection{Participants and locale}

The participants are five students and one female teacher. The students consist of one male and four female students of creative writing between 13-15 years old and in grades $8-10$ at the time of data collection. The locale is PHSA where the participants were enrolled and studying during the time of data collection. Their teacher was also interviewed as part of the data collection to further understand the importance of zinemaking for the youth and within the classroom.

The school, founded in 1978, serves as a specialized public high school that offers different arts-oriented programs such as creative writing, theater arts, visual arts, 
music, and dance. Students qualify through screening or audition, depending on the program that they aim to enter. PHSA is in Mount Makiling, Los Baños, Laguna.

Table 1. Participants and Materials

\begin{tabular}{|c|c|c|c|c|}
\hline Participant & Grade/Level & Zine Title & $\begin{array}{l}\text { Selections } \\
\text { (Materials) }\end{array}$ & Genre \\
\hline Mae* & & \multicolumn{3}{|c|}{ Creative Writing Teacher (PHSA) } \\
\hline \multirow[t]{10}{*}{ Ica* } & Grade 9 & Of Faces and & “Lungsod ng & Creative \\
\hline & & Places & Cotabato" & nonfiction \\
\hline & & & "South & \\
\hline & & & Cotabato" & \\
\hline & & & “Isla ng & \\
\hline & & & Samal" & \\
\hline & & & “Cagayan sa & \\
\hline & & & Norte" & \\
\hline & & & "Los Baños" & \\
\hline & & & "Lucban" & \\
\hline \multirow[t]{7}{*}{ Lara* } & Grade 9 & come back to & "Within & Fiction \\
\hline & & me, please & White Walls" & \\
\hline & & & "Playdate" & \\
\hline & & & "The Song of & \\
\hline & & & the Sevens" & \\
\hline & & & “Loose & \\
\hline & & & Threads" & \\
\hline \multirow[t]{4}{*}{ Dalisay* } & Grade 9 & Childhood & "Hopscotch" & Fiction \\
\hline & & Chapters & "Sorbete & \\
\hline & & & Story" & \\
\hline & & & "Chalk Dust" & \\
\hline \multirow[t]{2}{*}{ Ema* } & Grade 10 & Pinky Swear & "Transient & Creative \\
\hline & & & Homes" & nonfiction \\
\hline Nelson* & Grade 8 & Three Blind & “Tuyom” & Fiction \\
\hline
\end{tabular}


Reya Mari Soriaga Veloso | ASEAN Journal of Community Engagement | Volume 4, Number 1, 2020

\begin{tabular}{lcl}
\hline Participant $\quad$ Grade/Level & Zine Title & $\begin{array}{l}\text { Selections } \\
\text { (Materials) }\end{array}$ \\
\hline Men & \\
*Participants were encouraged to use self-chosen pseudonyms as an ethical \\
consideration for minors.
\end{tabular}

\subsection{Data collection methods}

This research employed qualitative methods such as focus-group discussion (FGD), face-to-face interviews, and thematic analysis of zines. FGD was conducted among all student-participants while face-to-face interviews were conducted individually, including an interview with their creative writing teacher. The interview and the focusgroup were unstructured to better elicit unfettered expressions from all the participants. There were no guide questions, but there were talking points or topics related to the objectives of the study, such as zines and YA literature, to give direction to the interviews.

Since the chosen participants were minors, ethical considerations required permission from the school and from their parents to participate in the study. The researcher sought and was granted permission by their school director, Mr. Victor Emmanuel Nadera, Jr. Following this, informed consent forms were given to the participants for their parents or guardians to sign. All consent forms given to each student were signed by their parents and/or legal guardians. The interviews were conducted and completed on February 27, 2018. The zine collection from various events and zine expos loosely took place from 2017 to 2018.

\subsection{Data analysis}

The study utilized qualitative content analysis to determine the themes and major concepts of the zines collected from the PHSA students. Content analysis focuses on regarding human activity as text, such as interviews and observational data and is interested in uncovering patterns of human activity, action, and meaning (Berg, 2001). Consequently, this research viewed students' literary zines and perzines (personal zines), along with their transcribed interviews and FGD, as texts to uncover themes and concepts of YA literature in their work. 
Two crucial elements in content analysis are manifest and latent. Manifest content is "physically present and countable"; it is gathered from what is readable in the participants' zines and interviews, while the latent or the "interpretative reading of the symbolism underlying the physical data" is examined from a closer reading of both interviews and zines (Berg, 2001). Uncovering the manifest and latent elements along with ensuring the reliability and validity of the data is possible through the triangulation of the focus-group, individual interviews, and literary materials from the students' zines.

Upon further examination of the zines, the researcher found that zines written by PHSA students create more structured pieces of fiction and creative nonfiction, thus solidifying the choice to study and analyze zines created by PHSA students. These pieces contained formal elements such as plot, characters, conflict, resolution, and motif that the reader became interested in for analysis as they reflect the current plight and struggles of the youth which are most seen in YA literature.

To further validate the themes arising from the zines of the participants, the help of an equipped data evaluator was sought. There were no disparities found between the work of the data evaluator and the researcher. Both were able to point out the major concepts and themes that resulted in the thematic typology of the study.

\section{Result and Discussion}

\subsection{YA Zines: An alternative creative community}

Some creative communities are embraced within the classroom, particularly if the teacher is radical enough to include materials and methods of learning that engage students beyond the rules and regulations of the syllabus. Some creative communities or groups are also formed from already existing art or literary organizations. There is no cookie-cutter formula in starting an alternative creative community: all one needs is a group of young people who are willing to create. This is parallel to what Duncombe (2008, p. 57-58) discusses in Chapter 3, "Community," of his book, "If community is traditionally thought of as a homogeneous group of individuals bound together by their commonality, a zine network proposes something different: a community of people linked via bonds of difference, each sharing their originality".

The experience of expressing themselves, creating and launching zines with their peers, and self-publishing all become possible through the alternative creative 
Reya Mari Soriaga Veloso | ASEAN Journal of Community Engagement | Volume 4, Number 1, 2020

community that zines and zine-making provides. While these young adults are known producers of zines, they are also active readers and consumers of the media. Therefore, in the relatively small literary communities facilitated by art collectives and other zinemakers, it is easier for these young adults to form connections and establish relationships with fellow zine-makers. De Gravelles et al. (2012) concludes that one of the primary goals of zinesters and zine institutions is fostering and building a community. While self-expression and creating new art is the product of zine-making, the study also reveals that establishing connections is pivotal in young people who create zines. They want to create, and they want an audience to see their creations.

They want to register their ideas, questions, concerns, rants, complaints, praise, and reflections on a platform that gives them agency, and at the same time to seek out others who are willing to discuss these with them. In zine-making, forming or establishing a community is inevitable: the connections one makes whether from a fellow creator to another or a creator to their audience, these connections are almost automatic once a zine is created. The zine functions as a text that instantly links young people together to form an alternative creative community from which they can establish deeper bonds and fellowship.

Through this investigation, it was discovered that zine-makers have three main goals: to express their ideas, to connect to other people through their work, and to resist or avoid the stringent requirements of mainstream publishing. These goals are easier to meet with the advent of social media, where advertising zine events or even just publicizing the release of one's new work is within the click of a button. Through the technologies available today, the facilitation of zine-making, and the fellowship of writers and creators, an alternative creative community becomes more attainable and accessible. Furthermore, zine-making as a literary practice is not just concerned with laying out zines or cutting and pasting, creating poems or stories for others to see. Instead, it is important to situate zine-making as a place where young adults find agency, fellowship, and authority.

\subsection{YA Zines: A form of counter-storytelling}

The works of fiction and nonfiction by young students from PHSA are a small but valid representation of experiences and struggles faced by the Filipino youth. As their stories discuss and tap themes such as homelessness and transience, building 
relationships, homesickness and nostalgia, identity formation through language, and even acts of subversion, they could be representing other young adults who are going through the same experiences. With this, it becomes a form of counter-storytelling as it challenges the foreign narratives that dominate the market and are more available for consumption especially for the youth. "Multicultural literature can not only challenge the single story [...] but also encourage and empower teens of color and indigenous peoples to take action in their own lives and in the world around them. It does this not by denying the hardship and prejudice that many of them face but by showing that, despite the disadvantages that correlate with their skin color, culture, and/or social class, they can overcome the constraints placed on them by the dominant culture as represented by the single story" (Hughes-Hassell, 2013). The themes unearthed from the works of these young adults are an urgent demand for space and agency as they claim their own literary genre.

This finding takes a step further into shaping Filipino YA literature: by being able to unearth the themes found in the fiction and nonfiction of PHSA students and determining their counter-storytelling characteristics, it is now evident that YA narratives are relevant and worthy of scholarship. Through zine-making, these young adults were able to self-publish themes, ideas, experiences, and even advocacies that may not be highlighted in commercially printed literature or textbooks. This goes to show that zine-making urges YA narratives, no matter how implicit, to be discussed not just in alternative creative communities, but also within the formal context of classroom learning. If the intention of using books and literature is to encourage students to develop reading as a lifelong habit or activity, what better tool to use for young adults than stories and literature that are reflective of their lived experiences?

If Filipino YA literature is considered a vital part of Philippine literature as informed by the trend of YA zines, its narrative would be more inclusive of the lived experiences of young adults in the country. More writers would also be encouraged to write about Filipino coming-of-age narratives, thus becoming a stronger force and form of counterstorytelling that could also inform how Philippine literature is taught within the classroom. 
Reya Mari Soriaga Veloso | ASEAN Journal of Community Engagement | Volume 4, Number 1, 2020

\subsection{YA Zines: The Coming-Of-Age themes in selected fiction and creative nonfiction}

\subsubsection{Permanence vs. transience}

The theme of Permanence versus Transience encompasses both works of creative nonfiction. Ema's “Transient Homes” depicts her frustration in their family's constant moves from one house to another. Her search for permanence, a place to finally call home, is evident as she details her frustration with each house. Every time, she compares every house or apartment she lives to her favorite house, the "White House." Her essay contains a definitive comparison of a house versus a home and why she will always long for home, a permanent dwelling to grow up and make countless and fruitful memories in.

Meanwhile, Ica's set of travel vignettes exudes a more comfortable tone on the prospect of a constantly moving and changing environment. She draws meaningful memories from visiting various places, such as establishing a deeper recognition of her family members, an acceptance of her love-hate relationship with her hometown and recalling intimate conversations with her closest friends. Ema and Ica view their surroundings differently and would expectedly have varied responses to the changes around them. This shows that their coming-of-age transition is not uniform and is dependent on their disposition and home life.

Since the theme of Permanence versus Transience is evident in the works of creative nonfiction, it prompts us to look deeply at the real-life experiences that these teens are narrating. How Ica and Ema perceive the world around them might also reflect how other teens or youths come-of-age. Socioeconomic factors such as diaspora and migration could affect how these young adults view their childhood. On the other hand, positive memories and experiences could also be formed as the result of traveling to places that have strong connections to one's family and roots.

Theme of making connections, building relationships is further subdivided into three categories: self and peers, self and family, self and society. In self and peers, it is evident that making friends is an important event that shapes one's childhood. This is evident in the variety of fiction and nonfiction pieces in this study. Making friends, or the difficulty thereof, is a recurring theme in some of these teens' stories. It shows that young adults crave connection as well as validation of themselves from the people around them, but mostly from their peers. In their stories, there are indications of hunger to build meaningful and lifelong relationships. 
Reya Mari Soriaga Veloso | ASEAN Journal of Community Engagement | Volume 4, Number 1, 2020

In self and family, it shows that their stories are mostly family oriented. Their stories are often filled with anecdotes about the family or sketches of close relatives who have made an impact in their lives. Their stories also draw out how much these young writers' value familial relationships and virtues such as respect, trust, and obedience.

It is also worth noting that the mother is a recurring character in stories such as "Transient Homes," "Lucban," "Loose Threads," "Playdate," "Song of the Sevens," "Shower," "Chalk Dust," and "Tuyom." The appearance of the mother as a character varies in that sometimes she is just mentioned and other times, she delivers a dialog or has a constant interaction with the narrator or main character. This suggests that the stories show an appreciation for the maternal presence or that the writers simply value the roles of their mothers in their lives enough to allow her to be a constant character in their stories. In stories such as "Loose Threads," "Playdate," and "Shower," the mother is depicted as a source of authority as well as nurturing and care, which reflects how most Filipino families operate.

In self and society, characters are depicted as recognizing their roles through family and peers, and the main characters of the stories also provide glimpses of how they make sense of the world around them-that they occupy a larger space of responsibility outside family and friends. In these minute glimpses, the characters show their middleclass privilege as well as the socioeconomic differences between them and the people around them.

These instances of privilege and reflection on their socioeconomic standing might help in making them a more responsible and well-rounded individuals as they grow up. By becoming aware that they are entitled to some form of freedoms that are not available to other teens, and by being able to distinguish the different socioeconomic standings of young adults like them who live in the Philippines, they could be more predisposed to gaining a deeper understanding of their role as young adults in the Philippine society and therefore keener on inspiring positive changes in and for the world around them. 
Reya Mari Soriaga Veloso | ASEAN Journal of Community Engagement | Volume 4, Number 1, 2020

\subsubsection{Homesickness and nostalgia}

In "Transient Homes," Ema utters statements such as "There's something special about having your own permanent home." She also says that she lost her appetite when they moved to Saudi Arabia: "The food I was eating belonged to the Philippines and eating it just made me want to come home to my country." Furthermore, she stresses that, "It was oppressive being there and I wanted nothing more than to go back home to the Philippines." These utterances in her essay exhibit great yearning to finally find a permanent home as well. Another instance of homesickness appears in "Chalk Dust," where Tia experiences homesickness when drawing on the sidewalk with chalk. She feels that the chalk dust is her strongest connection to her home in Ilocos.

In "Playdate," Kenny's frequent visits to the favorite spot of his late playmates and the way that he would proceed to narrate stories about himself to them is a manifestation of nostalgia. By frequently visiting and narrating stories to his dead playmates, he shows deep yearning and hope to bring them back and play with them again. In "South Cotabato," while basking in the scenery of the pineapple plantation, Ica recalls how similar it is to her childhood paintings. In "Los Baños," she describes how a place can remind you of a person close to you. In "Lucban," she states that writing about her hometown is one of the only ways she could remain connected to the place.

For these teens, memories play a crucial role in their transition to adulthood as it helps inform their disposition and personality as they grow up. These young adults display earnestness when it comes to remembering poignant and positive memories. They exhibit a form of maturity as they learn to express emotions and recall memories, places, and persons that they long for.

\subsubsection{Language as a tool in shaping identity}

In stories such as "Transient Homes," "Lucban," and "Sorbete Story," the authors express and narrate how language facility, or a lack thereof, informs their consciousness. In "Transient Homes," Ema expresses her frustration and the rejection she felt when she was punished for speaking in Filipino even though she was enrolled in a Filipino school in Saudi Arabia. She was upset that she was not allowed to speak and practice the only language that she felt connected her most to her home country. In "Lucban," Ica narrates that upon arriving home on weekend, she was saddened by the fact that her brother's Lucbanin accent had got stronger. Throughout the vignette, she 
details her own frustration at never learning the accent herself, something that has caused her neighbors and relatives to question if she was truly a Lucbanin. In "Sorbete Story," the main character realized that learning the Ilokano dialect would make it easier for her to fit in and that people would treat her differently if they found out that she was not a native of the region. Such instances in the stories of these young writers show that learning their own language or dialect is crucial in forming their identitiesare they truly Filipino, Lucbanin, or Ilokano if they are not connected to the language being spoken? Learning the language or dialect also affects how they fit in with the people around them.

These instances show that language is a crucial factor in young adults as they comeof-age. It determines how they will view themselves and also how other people would perceive them. Their knowledge and fluency of their own language or dialect will also affect or influence their connection to their hometown and their overall sense of belonging.

\subsubsection{Acts of subversion}

In the stories written by young adults, acts of subversion are present through verbal remarks or certain actions. These subversions are not necessarily violent or offensive but are a form of questioning or challenging the authorities around them, such as parental, household, or societal rules. These acts of subversion could also be regarded as young adults claiming their agency or independence in a world that is usually governed by adults.

In "Transient Homes," Ema lies to her parents about finishing her food hides it under the couch. She says that she was implicitly enforcing "a hunger strike" while in Saudi Arabia because her body and appetite yearns to go back home to the Philippines. In "Isla ng Samal," Ica makes snide remarks about being adopted to her cousin Darlene in her frustration over trying to establish a deeper connection with her cousin. In "Within White Walls," Gabriel questions the existing rules enforced by the robot he encounters and the seemingly totalitarian society he wakes up in. In "The Song of the Sevens," Leon continues to try and prove himself even though he knows that his mother will not approve of it. In "Shower," the main character and her siblings assert their authority by taking a shower in the rain despite their mother's admonition against it. 
Reya Mari Soriaga Veloso | ASEAN Journal of Community Engagement | Volume 4, Number 1, 2020

It is important to view these acts with reason rather than with judgment when it comes to young adults seeking and claiming their independence and their own authority. Most of the time, adults enforce rules without explanation. When young people commit acts of subversion, it does not simply mean rebellion. Often, it is just a manifestation of their curiosity and a wish to understand the world around them.

\subsection{YA Zines: A Means for collecting smaller histories}

The works of nonfiction and fiction by the young adults of PHSA not only contribute to the field of literature, art, and media, but they are also significant contributions to sociological theorizing and therefore to reflecting our larger social realities. According to Erasga (2010), works of nonfiction or individual biographies should be examined as part of a larger history, while works of fiction should be viewed at as a legitimate reflection of the reality of the social milieu. The works of these PHSA students should be looked at not just as anecdotes or figments of their imagination, but rather as their contribution in describing and participating in the current social reality they belong to. As they write about finding home, building relationships, nostalgia, language as an identity-shaper, and small acts of rebellion, their stories carry not just their individual voices, but it sounds the call to other young adults who are possibly going through the same things.

The stories of these young adults contain themes that are not just confined in the zines that they create. The themes that their stories contain are reflections of our reality and are part of the smaller histories that when collected and properly documented, will translate into our national history as well. Youth are an integral part of our national history-their struggles and motivations shape the landscape of what our future as a nation will be. The stories that these young people write must be read, heard, and addressed for they contain pieces of reality that are often, missing from the commercial and mainstream narratives that are consumed by most.

Encouraging more youths to participate in zine-making and forming alternative creative communities plus urging educators to include more young adult narratives in the classroom are just the preliminary stages of inspiring change. Researchers could further study youths who come from more marginalized sectors whose stories, when put in writing, would reflect their social milieu and inspire institutions and services to improve the welfare and conditions of all the youths in our country. 
This study is reflective of how the landscape of literature and alternative publishing spaces are expanding in the Philippines. More young adults now have the avenue to publish their own works and to gain readership and fellowship in establishing creative communities in the practice of zine-making. This paper was also able to highlight that young adult literature should be granted a space in the literary community and even the classroom, as the genre is crucial to the literary development of young adults.

\section{Conclusion}

Based on the findings and analysis, the researcher concludes that zine-making provides an alternative community to young adult writers, that the stories and pieces they write are a form of counter-storytelling, and that the themes unearthed from these zines are means for collecting smaller histories and reflecting the current social milieu based on the works of nonfiction and fiction. As in all studies, several limitations exist in this research.

First, the findings are based on self-reporting. However, self-reporting is the best means of eliciting answers and in enabling the development of a general understanding of the issues. Second, the sample students are enrolled in a special high school for the arts and come from families that have a higher socioeconomic status than the general population. This could have a bearing on their perception of events and the world around them. Third, since purposive sampling is employed, it is unclear whether the sample is an accurate representation of the greater population. To address these limitations, the researcher suggests a more inclusive sampling of youths from different sociological backgrounds, seeking help from more than one data reviewer, and finally, including other literary genres such as poetry, comics, etc., for analysis.

As recommended, further replications of this study could include solidifying a zinemaking workshop as a tool for communicating with and among patients of mental health illnesses, drug rehabilitations, and out-of-school youths. As different sectors and members of society participate in zine-making workshops, more themes would be uncovered, thus enriching the collection of smaller histories in the nation. Creative communities among the youth in the Philippines are continuously thriving. Events and creative spaces such as BLTX and Zine Orgy and even creative writing classes in high schools and universities provide the youth with avenues for them to create, forge fellowships, and express themselves with agency through their literary and artistic 
Reya Mari Soriaga Veloso | ASEAN Journal of Community Engagement | Volume 4, Number 1, 2020

works. These creative communities' function as discursive spaces, allowing our youth to carve for themselves a world that is truly their own. As scholars, it is our responsibility to hone and discover new discursive spaces and creative communities so that our youth could continue to enrich their lives through these constant avenues for creation.

\section{Author Contribution}

Reya Mari S. Veloso is the sole author of this paper. All ideas were conceived and executed by the author.

\section{Acknowledgments}

This paper would not be possible without the continuous guidance of my academic adviser Dr. Larcy C. Abello, and panel members, Drs. Leonora M. Fajutagana and Florencia G. Palis, and Prof. Girlie A. Abrigo. I would like to thank Mr. Victor Emmanuel Nadera, Jr., whose permission allowed me to facilitate this study with students from Philippine High School for the Arts. Thank you, Ms. Rae Rival-Cosico for the privilege to interview your students and for the meaningful conversations about zine-making, literature, and today's youth. To Ica, Ema, Lara, Dalisay, and Nelson: my work would not have come to fruition without yours. Please never stop writing and creating.

\section{References}

Alsup, J. (2010). Identification, Actualization, or Education: Why Read YAL? In J. Alsup (Ed.), Young Adult Literature and Adolescent Identity Across Cultures and Classrooms: Contexts for the Literary Lives of Teens, (pp. 1-16). New York: Routledge.

Basug, V. D., \& Bongalbal, J. T. (2007). Digging the Underground: A Historical Study of

Metro Manila Zines From 1987 to 2004 (undergraduate thesis). University of the Philippines, Diliman, Quezon City: Philippines.

Banzon, C. (2015, August 24). Metro Manila's zine culture in 10 quick points. Retrieved from Coconuts Manila:

https://coconuts.co/manila/features/metro-manilas-zine-culture-10-quick-points/

Berg, B. L. (2001). Qualitative research methods for the social sciences. Needham Heights, MA: Allyn \& Bacon. 
Bongato, I. L., \& Ting, J. P. (2014, August 20). Bringing the genre home.

http://www.theguidon.com/1112/main/2014/08/bringing-genre-home/

Butow, P., Palmer, S., Pai, A., Goodenough, B., Luckett, T., \& King, M. (2010). Review of Adherence-Related Issues in Adolescents and Young Adults With Cancer. Journal of Clinical Oncology, 28(32), 4800-4809.

https://pubmed.ncbi.nlm.nih.gov/20212260/

Cabral, A. (2017, August 30). How the zine can be a tool for social change.

http://cnnphilippines.com/life/culture/literature/2017/08/30/zine-making-adamdavid.html

Cabral, A., \& Ledesma, I. (2016, December 19). The power of the small press: On selfpublishing in the digital age.

http://cnnphilippines.com/life/culture/literature/2016/12/19/bltx-adamdavid.html

Chu, J. (1997). Navigating the Media Environment: How Youth Claim a Place Through Zines. Social Justice, 24(69), 71-85.

https://www.jstor.org/stable/29767022

Comstock, M. (2001). Grrrl Zine Networks: Re-Composing Spaces of Authority, Gender, and Culture. JAC, 21(2), 383-409.

http://www.jstor.org/stable/20866409

de Gravelles, K. H., Bach, J., Hyde, Y., Hebert, A., Hale, D., Cavanaugh, A., \& Kimbrough, M. (2012). Novelzine: Reading and Writing Community. The English Journal, 101(4), 5563.

http://www.jstor.org/stable/41415474

Deleuze, G., \& Guattari, F. (2003). Kafka: Toward a minor literature. Minneapolis: University of Minnesota Press.

Doll, J. (2012, April 26). The ongoing problem of race in Y.A.

https://www.theatlantic.com/entertainment/archive/2012/04/ongoing-problemrace-y/328841/

Duncombe, S. (2008). Notes from underground: Zines and the politics of alternative culture (2nd ed.). Bloomington, Portland: Microcosm Publishing. 
Reya Mari Soriaga Veloso | ASEAN Journal of Community Engagement | Volume 4, Number 1, 2020

Erasga, D. S. (2010). When Story Becomes Theory: Storytelling as Sociological Theorizing. Asia-Pacific Social Science Review, 10(1), 21-38.

https://ejournals.ph/article.php?id=5930

Estrella, F. (2016, April 14). The tactile pleasures of zines.

http://cnnphilippines.com/life/culture/arts/2016/04/14/binding-exhibit.html

Geiger, A. M., \& Castellino, S. M. (2011). Delineating the Age Ranges Used to Define Adolescents and Young Adults. Journal of Clinical Oncology, 29(16), e492-e493.

https://pubmed.ncbi.nlm.nih.gov/21482981/

Golez, R. (2014, October 23). Herald X - Alternative Music Read n 1 - 1987.

http://philippines80shardcore.blogspot.com/2014/10/herald-X-alternative-musicread-n1-1987.html

Guzzetti, B. J., \& Gamboa, M. (2004). Zines for Social Justice: Adolescent Girls Writing on Their Own. Reading Research Quarterly, 39(4), 408-436.

https://www.jstor.org/stable/4151741

Hayn, J. A., Kaplan, J. S., \& Nolen, A. (2011). Young Adult Literature Research in the 21st Century. Theory Into Practice, 50(3), 176-181.

https://www.tandfonline.com/doi/abs/10.1080/00405841.2011.584026

Howlett, G. (2015, February 24). Why are so many adults reading YA and teen fiction?

https://www.theguardian.com/childrens-books-site/2015/feb/24/why-are-somany-adults-reading-ya-teen-fiction

Hughes-Hassell, S. (2013). Multicultural Young Adult Literature as a Form of CounterStorytelling. The Library Quarterly: Information, Community, Policy, 83(3), 212-228. https://www.jstor.org/stable/10.1086/670696

Lymn, J. (2014). Queering Archives: The Practice of Zines (dissertation). University of Technology, Sydney: Australia.

https://researchoutput.csu.edu.au/en/publications/queering-archives-thepractices-of-zines-3

Marcoux, B. (2004). Genres for Young Adult Literature (lecture notes). The Information School of the University of Washington.

http://www.csun.edu/ tcb69252/files/ppt/Genres_for_Young_Adult_Literature1.ppt 
Mojares, R. B. (2015). Inside Out, Outside In: Teaching World Literature Through Philippine Literature. Kritika Kultura, 24, 228-239.

https://journals.ateneo.edu/ojs/index.php/kk/article/view/KK2015.02408

Piepmeier, A. (2008). Why Zines Matter: Materiality and the Creation of Embodied Community. American Periodicals, 18(2), 213-238.

\section{http://www.jstor.org/stable/41219799}

Rogers, T., \& Marshall, E. (2012). On the Road: Examining Self-Representation and Discourse of Homelessness in Young Adult Texts. Journal of Adolescent \& Adult Literacy, 55(8), 725-733.

\section{https://ila.onlinelibrary.wiley.com/doi/10.1002/JAAL.00087}

Santoli, S. P., \& Wagner, M. E. (2004). Promoting Young Adult Literature: The Other "Real" Literature. American Secondary Education, 33(1), 65-75.

\section{http://www.jstor.org/stable/41064624}

Siriban, D. R. (2010). Zines in Philippine Punk Culture: A Textual Analysis of Creative

Nonfiction in Southern Tagalog Zines (master's thesis). University of the Philippines, Diliman, Quezon City: Philippines.

Torres-Yu, R. (2011). Childhood and Family in Contemporary Children's Fiction: Resilience, Agency, and Emergence of New Gender Norms. Kritika Kultura, 16, 44-64. https://journals.ateneo.edu/ojs/index.php/kk/article/view/1432

Trupe, A. (2006). Thematic Guide to Young Adult Literature. Westport, Connecticut: Greenwood Press.

Wolk, S. (2009). Reading for a Better World: Teaching for Social Responsibility With Young Adult Literature. Journal of Adolescent \& Adult Literacy, 52(8), 664-673. https://ila.onlinelibrary.wiley.com/doi/10.1598/JAAL.52.8.2

Zdilla, G. (2010). The Appeal of Young Adult Literature in Late Adolescence: College Freshmen Read YAL. In J. Alsup (Ed.), Young Adult Literature and Adolescent Identity Across Cultures and Classrooms (pp. 191-203). New York: Routledge.

Zobl, E. (2009). Cultural Production, Transnational Networking, and Critical Reflection in Feminist Zines. Signs, 35(1), 1-12. 